http://jmscr.igmpublication.org/home/ ISSN (e)-2347-176x ISSN (p) 2455-0450

crossref DOI: https://dx.doi.org/10.18535/jmscr/v8i6.09

\title{
Elevated CRP (C-Reactive Protein) Values in Orthopaedic Implant Infected Patients
}

\author{
Authors \\ Dr Ramanujam $\mathbf{P}^{1}$, Dr Sabarisree. $\mathbf{M}^{2}$ \\ ${ }^{1}$ Associate Professor (CAP), in Orthopaedics, Government Medical College, Trivandrum \\ ${ }^{2}$ Additional Professor in Orthopaedics, Government Medical College, Trivandrum
}

\begin{abstract}
Background: Orthopaedic implant infections are a common problem in all major orthopaedic units. Established implant infections can be evaluated with clinical and biochemical parameters.

CRP C-Reactive protein is an acute phase reactant. Normal value is $0-5 \mathrm{mg} /$ Litre. Values above $10 \mathrm{mg} /$ Litre are suggestive of definite implant infection.

Reduction intitrecorrelates with control of infection.

This study aims to study the correlation between implant infections and CRP levels in a government hospital.

Materials and Methods: This is a retrospective study of fifty patients who were admitted with various types of orthopaedic implant infections. This include Hip and knee joint arthroplasties, DCP, plates, intramedullary nails.

Results: All implant infections had CRP values above $20 \mathrm{mg} / \mathrm{L}$ response to antibiotic suppression of infection reduced CRP to values below $10 \mathrm{mg} / \mathrm{L}$.

Conclusion: CRP is a good marker of implant related infection both for diagnosis and monitoring the results of antibiotic treatment.
\end{abstract}

\section{Introduction}

Implant related infection in orthopaedics presents with, pain, redness, discharge biochemical parameters like ESR, CRD, IL-6 are acute phase reactants, their levels are elevated in all infections. CRP is more reliable than ESR.

An elevated level of CRP above $10 \mathrm{mg} /$ litre is taken as a proof of implant related infection.

Reduction in the titres can be used to monitor the response to antibiotics. CRP measurement is more reliable than ESR and other acute phase reactants.

\section{Objectives}

1. To identity whether CRP is elevated in all cases of orthopaedic implant infection.

2. Whether the titres of CRP are reduced following Antibiotic therapy.

\section{Materials and Methods}

Patients with orthopaedic implant related infection admitted to the orthopaedic wards during the period of 1 year may $2019 \rightarrow$ May 2020 Implant infections means those infections presenting 3 months after surgery. 


\section{Inclusion Criteria}

1. All orthopaedic implant infections presenting 3 months after surgery.

2. Arthroplasty infections.

\section{Exclusion Criteria}

1. Immediate post operative infections.

2. Minor implants like K-wire fixation.

3. External fixator pin tract infections

4. Patients already having chronic osteomyelitis.

\section{Results}

A total of fifty patients were analyzed. All of them had elevated CRP levels in the range of $20-40 \mathrm{mg}$ /L. All the patients responded to suppressive
Antibiotic therapy as evidenced by reduction in titre values.

Arthroplasty infections were found to be controlled as reduction in titre were evident only after 6 weeks.

Younger patients - less than 40 years showed marked response in titre reduction presence of other co-morbidities especially diabetes mellitus showed a slower rate return to base time levels.

\section{Gender Wise Analysis}

Male - 40

Female -10

Type of Implants used which were infected

\begin{tabular}{|l|l|}
\hline Dynamic compression plates & 20 \\
\hline Intramedullary Nails for Femur and tibia & 20 \\
\hline Arthroplasties (Hip and knee) & 10 \\
\hline
\end{tabular}

C.R.P. Values in the initial stages of presentation

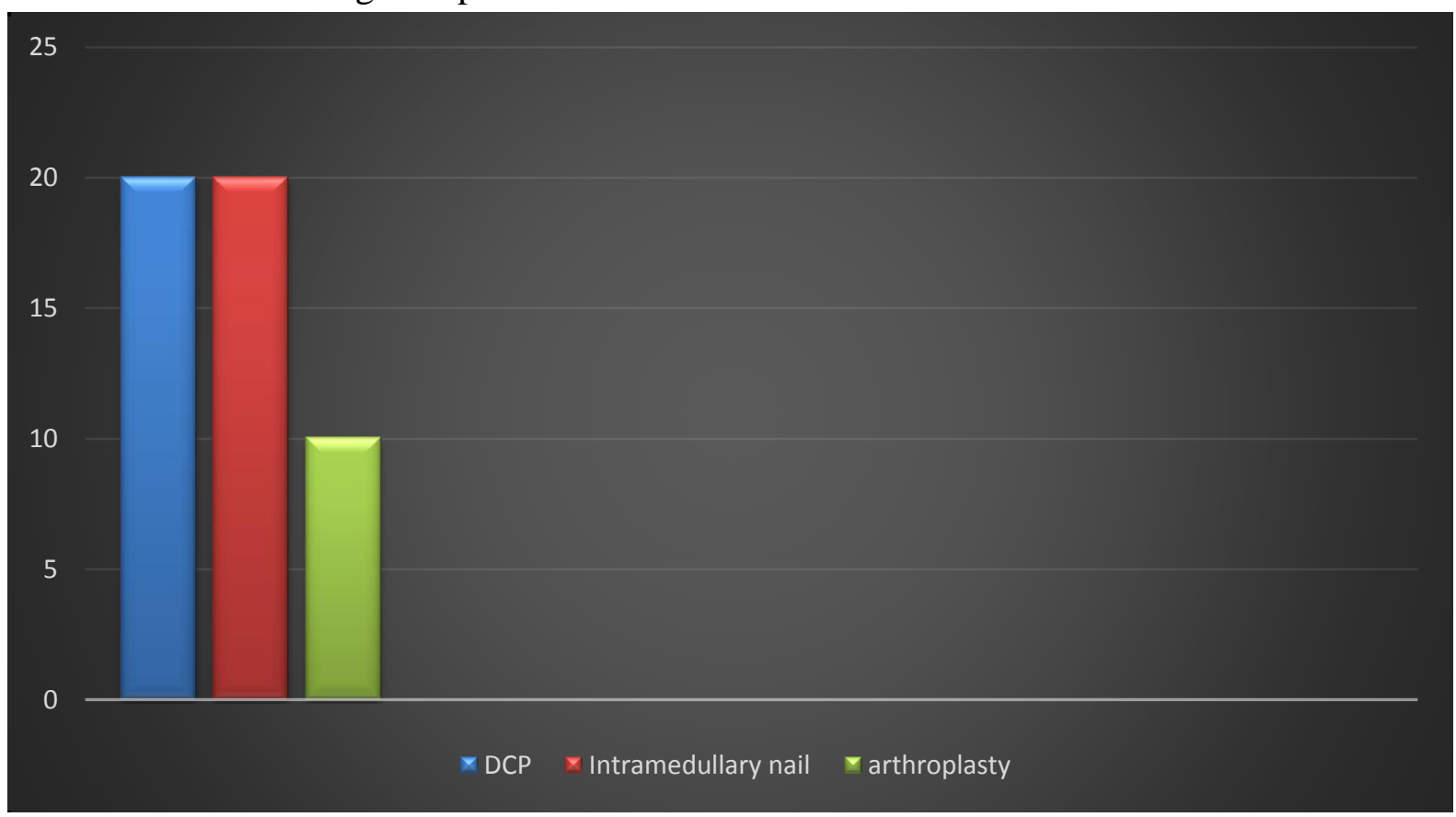

No. patients

\begin{tabular}{|l|c|c|}
\hline Age groups patients profile & Type of implants & Number \\
\hline $20-40$ & D.C.P. & 18 \\
\hline $40-60$ & Intramedullary nails & 22 \\
\hline $60-80$ & Arthroplasties & 10 \\
\hline
\end{tabular}

Presence of co-morbidities

\begin{tabular}{|l|c|}
\hline Diabetes mellitus & 30 \\
\hline Peripheral vascular disease & 5 \\
\hline COPD & 3 \\
\hline Steroids & 3 \\
\hline Hypertension and others & 9 \\
\hline
\end{tabular}




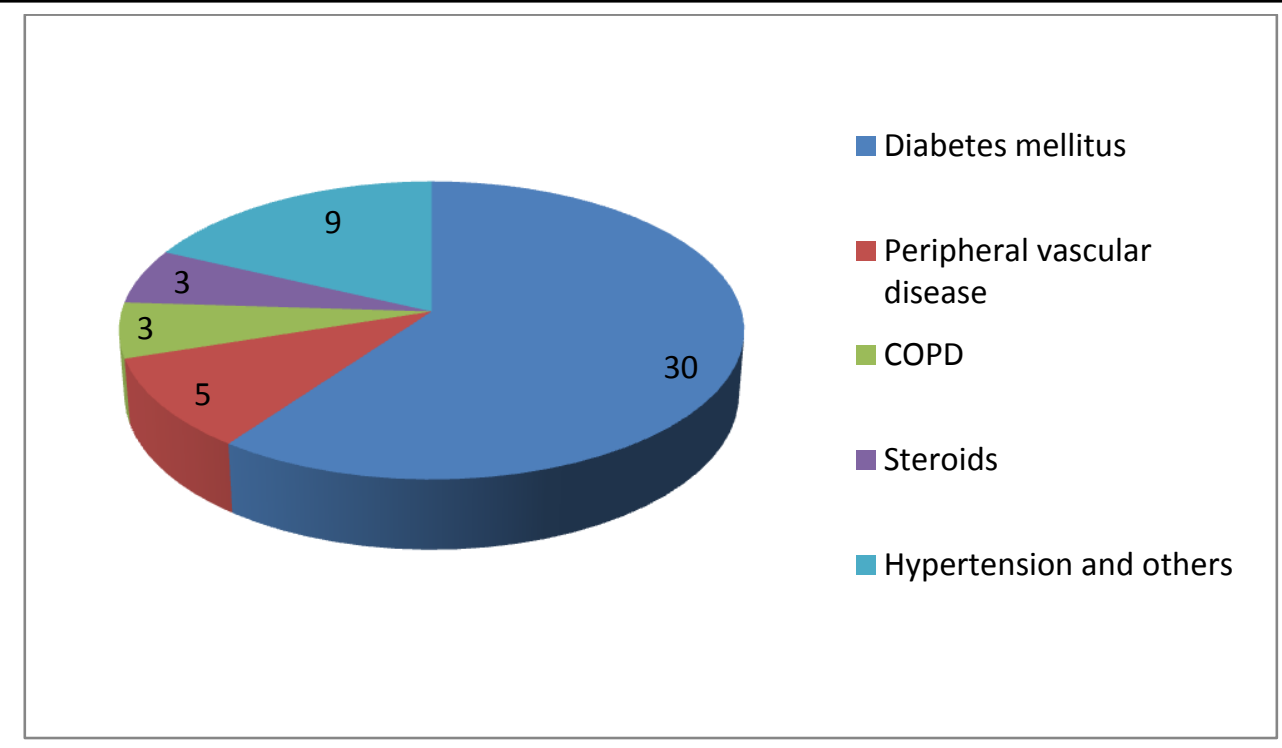

Response to suppressive Antibiotic therapy in weeks

\section{Repeat titres were taken at 2 (14 days) week in Response period}

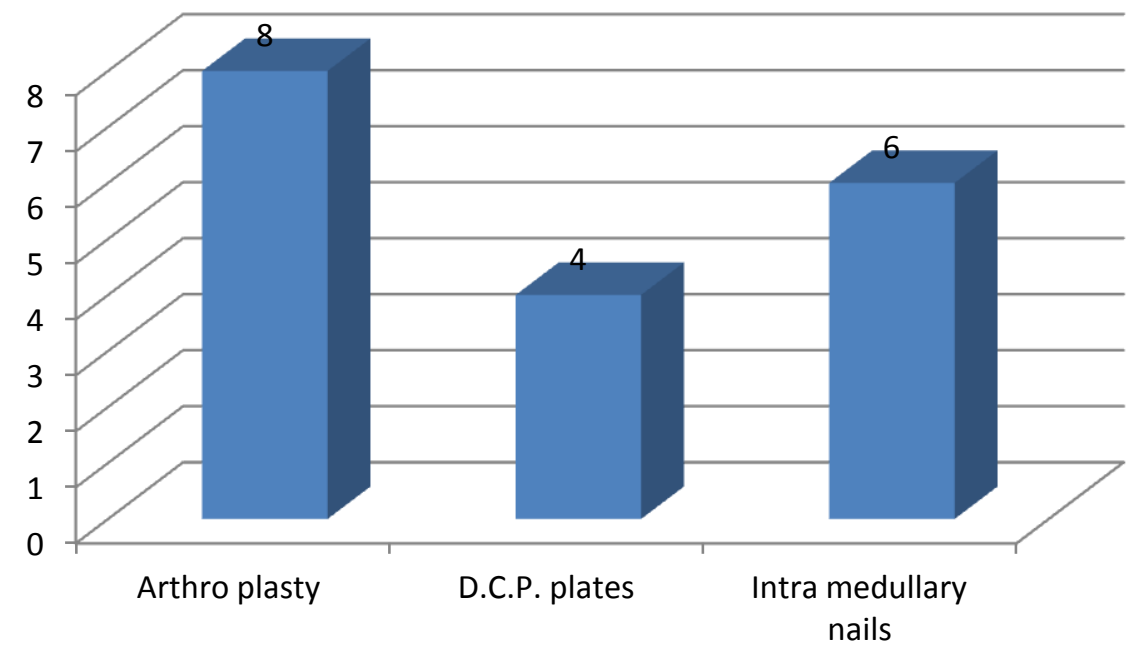

Age Distribution of Response To Treatment - as shown by Fall in CRP titres

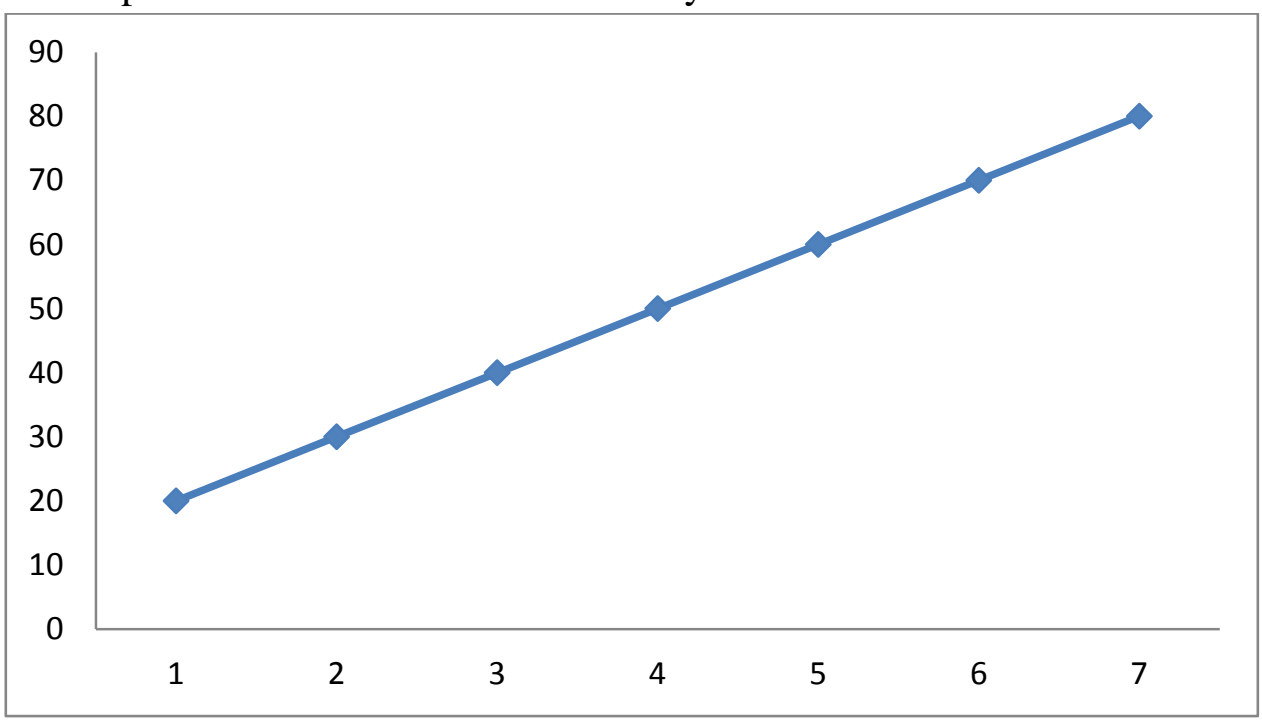




\section{Discussion}

As shown by the results CRP level estimation and follow up of the titres at an interval of two weeks helps to establish the presence of an implant related infection and the response to Antibiotic therapy.

The younger age group showed a good response whereas the older age group patients who underwent arthroplasties showed a delayed response to treatment.

The presence of co-morbidities in the older age groups could be one of the reasons for the slow response.

However the CRP titres invariably reduced indicating a remission.

CRP titres were very much raised in arthroplasty group of patients but were nearly the same in other type of implants.

\section{Conclusion}

Monitoring CRP levels at the time of presentation and regular follow at intervals of two weeks helps to monitor the response to treatment CRP is a useful marker to identity and monitor treatment response age and comorbidities tend to delay the response to treatment however CRP level usually declining to near baseline levels in six to eightweeks time.

\section{References}

1. Ghanem. E. Antoci V-Analysis of ESR, CRP in diagnosing periprosthetic infectious prior to revision arthroplasty2019.

2. Piper. K.E. Fernandez, steekleberg-C.R.P \& ESR in orthopaedic implant infection 2015 (Pubmed).

3. Greidanus N V Masri B A etal use of ESR, CRP level to diagnosis infection before revision total knee arthroplasty 2007 (Pubmed).

4. Costa CR, Johnzon, Nazim. Efficacy of CRP level in determining periprosthetic Hip infections 2013 (Pubmed).
5. Johnson AJ, Zyniel M.G. Stron. A, serologic marker can lead to False negative Diagnosis of periprosthetic infections 2012 (Pubmed).

6. Simon. E. Gauvin. F. Amre DK CRP and Serum procalcitonin levels as markers for orthopaedic infections 2004 (Pubmed). 